\title{
Guided bone augmentation using ceramic space-maintaining devices: the impact of chemistry
}

This article was published in the following Dove Press journal:

Clinical, Cosmetic and Investigational Dentistry

12 March 2015

Number of times this article has been viewed

\author{
Jonas Anderud ${ }^{1,2}$ \\ Peter Abrahamsson ${ }^{2}$ \\ Ryo Jimbo' \\ Sten Isaksson ${ }^{2}$ \\ Erik Adolfsson ${ }^{3}$ \\ Johan Malmström² \\ Yoshihito Naito ${ }^{4}$ \\ Ann Wennerberg' \\ 'Department of Prosthodontics, \\ Faculty of Odontology, Malmö \\ University, Malmö, Sweden; \\ ${ }^{2}$ Maxillofacial Unit Halmstad, Region \\ Halland, Halmstad, Sweden; ${ }^{3}$ Swedish \\ Ceramic Institute, IVF, Mölndal, \\ Sweden; ${ }^{4}$ Department of Oral and \\ Maxillofacial Prosthodontics and \\ Oral Implantology, Institute of Health \\ Biosciences, University of Tokushima \\ Graduate School, Tokushima, Japan
}

Correspondence: Jonas Anderud

Department of Prosthodontics,

Faculty of Odontology, Malmö

University, 20506 Malmö, Sweden

$\mathrm{Tel}+46706212961$

Email jonas.anderud@regionhalland.se

\begin{abstract}
The purpose of the study was to evaluate histologically, whether vertical bone augmentation can be achieved using a hollow ceramic space maintaining device in a rabbit calvaria model. Furthermore, the chemistry of microporous hydroxyapatite and zirconia were tested to determine which of these two ceramics are most suitable for guided bone generation. 24 hollow domes in two different ceramic materials were placed subperiosteal on rabbit skull bone. The rabbits were sacrificed after 12 weeks and the histology results were analyzed regarding boneto-material contact and volume of newly formed bone. The results suggest that the effect of the microporous structure of hydroxyapatite seems to facilitate for the bone cells to adhere to the material and that zirconia enhance a slightly larger volume of newly formed bone. In conclusion, the results of the current study demonstrated that ceramic space maintaining devices permits new bone formation and osteoconduction within the dome.
\end{abstract}

Keywords: hydroxyapatite, zirconia, guided bone regeneration, GBR, histology, membrane

\section{Introduction}

When teeth are missing and the function of chewing is compromised, the missing teeth can be replaced with implant-supported prostheses. To allow a successful implantation, the jaw bone needs to be sufficient in quality and volume. ${ }^{1,2}$ If the bone volume is insufficient, it can be increased by transplanting bone and/or supplementing with a bone substitute. ${ }^{3}$ Guided bone regeneration (GBR) is defined as creating a space between the bone and surrounding soft tissues using a barrier that allows new bone to migrate into the space while preventing other tissue from so doing. ${ }^{4,5}$ It was originally described by Nyman et $\mathrm{al}^{5}$ and later by Gottlow et al. ${ }^{4}$ Barriers of different materials have been suggested for this purpose and have been evaluated in scientific publications, of which titanium-enforced Gore-Tex (ePTFE) is one of the first materials reported. ${ }^{6}$ Titanium mesh of various shapes and designs has also been used, often in combination with transplanted bone. ${ }^{7}$

The barrier used needs to have a satisfactory biocompatibility, meaning the ability to be accepted by the tissues without causing any adverse reactions or infections. Another criterion is the ability to fit to the surface, allowing bone cells to migrate without disruption by movement caused by oral functions. A third criterion is the ability to block out the soft tissue from the cavity that has been created, while still allowing bone cells and vessels to migrate and grow. ${ }^{8}$

Titanium-reinforced Gore-Tex membranes meet the first and third criteria. However, they have limited ability to remain stable against the surface, especially when larger areas are to be reconstructed, which can jeopardize the results. Titanium meshes can 
be used for creating bone for areas larger than a one-tooth gap, but usually require that particulate or block bone is transplanted to the area. Yet the use of titanium mesh has shown complications, in that it penetrates the oral mucosa, which could lead to an esthetically unsuccessful result. ${ }^{9}$ This seems to be avoided when placing a biodegradable membrane over the mesh to prevent the soft tissues from growing into it. ${ }^{10}$ Therefore, it seems necessary to investigate the importance of an occlusive and smooth outer surface of the membrane used.

Based on this knowledge, it was of great interest to investigate a novel method of vertical and horizontal bone augmentation using biocompatible ceramic materials designed as barriers. Ceramics are inorganic nonmetallic materials that have specific properties, such as hardness, brittleness, poor conductivity, and high melting temperature. More detailed information can be found elsewhere. ${ }^{11}$

The purpose of the study was to evaluate histologically, with light microscopy and scanning electron microscopy (SEM), whether vertical bone augmentation can be achieved using a hollow ceramic space-maintaining device in a rabbit calvaria model. Furthermore, the chemistry of microporous hydroxyapatite and zirconia was tested to determine which of these two ceramics is most suitable for GBR.

\section{Materials and methods \\ Materials}

Twelve hollow domes made of zirconia and 12 hollow domes made of microporous hydroxyapatite with interconnected pores were manufactured (Figures 1-3). They were shaped

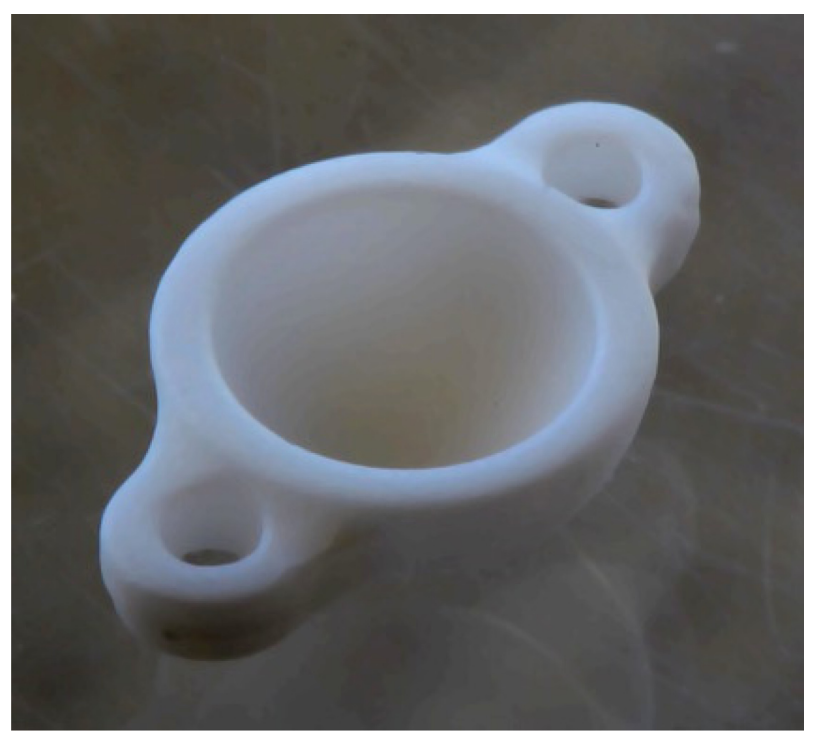

Figure I The zirconia space-maintaining device.

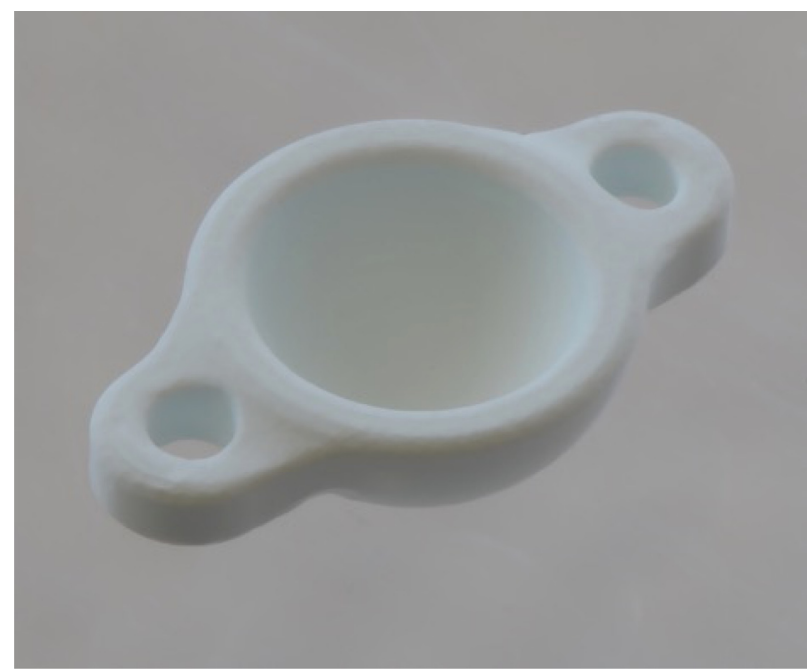

Figure $\mathbf{2}$ The microporous hydroxyapatite space-maintaining device.

as half spheres with an inner diameter of $6 \mathrm{~mm}$ and an outer diameter of $8 \mathrm{~mm}$.

The ceramic components were produced from a hydroxyapatite powder (Plasma Biotal, Buxton, UK), which was further processed with water and dispersant (polyacrylic acid) to prepare a ceramic suspension by ball milling. To obtain a hydroxyapatite powder suitable for compaction, the ceramic suspension was freeze granulated. Ceramic green bodies of hydroxyapatite and zirconia (TZ-3YB-E, Tosoh) were prepared by isostatic compaction of the powder at a pressure of $300 \mathrm{MPa}$. The sintering shrinkages of both materials were measured and used to compensate the enlargement of the computer-aided design model in order to ensure that the sintered components of hydroxyapatite and zirconia had the same size as the designed model. Based on the rescaled computer-aided design models, a five-axis $\mathrm{CNC}$ machine was used to machine green bodies of both materials to the desired macroscopic size and shape. The microporous hydroxyapatite surface was produced by presintering the machined material at $900^{\circ} \mathrm{C}$ for 2 hours, blasting with $110 \mu \mathrm{m}$ alumina particles at 1 bar and an additional heat treatment at $900^{\circ} \mathrm{C}$. The zirconia surface was produced by presintering at $900^{\circ} \mathrm{C}$ and machined and sintered at $1,450^{\circ} \mathrm{C}$ for 2 hours.

\section{Surface topography}

The topography of the inner surface of the space-maintaining devices was characterized using an interferometer (MicroXam; ADE Phase Shift Technology, Inc., Tucson, AZ, USA). Three devices per group were randomly selected for analysis. Each device was measured at five positions (one at the most inner top and four at the flank areas). The parametric calculation was performed after form errors and waviness 


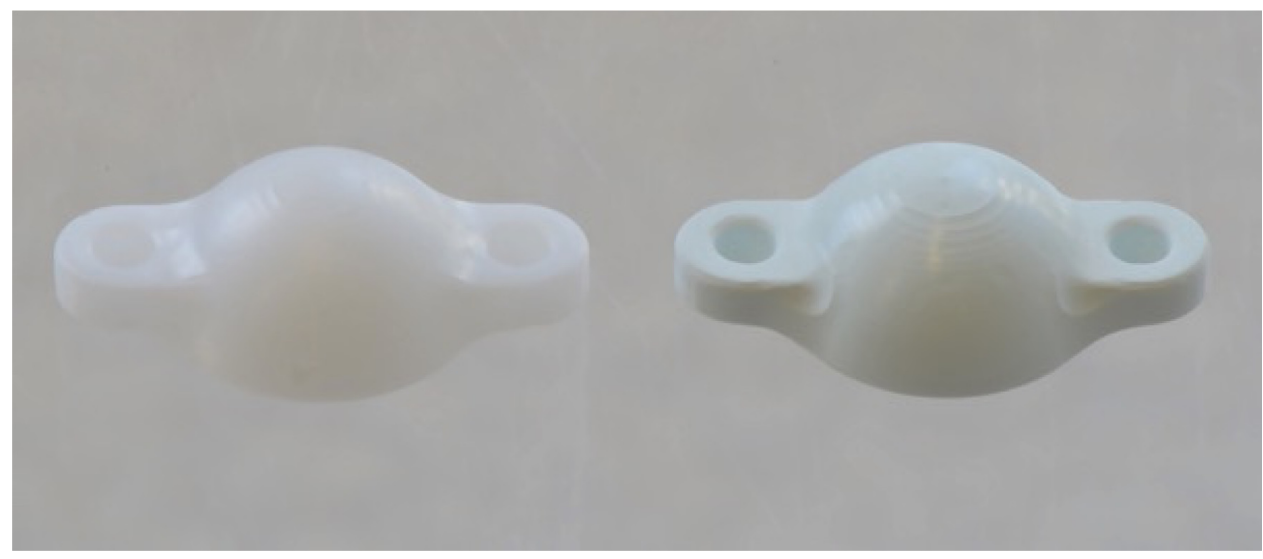

Figure 3 The two different ceramic space-maintaining devices (zirconia to the left and microporous hydroxyapatite to the right).

were removed with a $50 \mu \mathrm{m} \times 50 \mu \mathrm{m}$ Gaussian filter. The following three-dimensional parameters were selected: $\mathrm{S}_{\mathrm{a}}$ $(\mu \mathrm{m})=$ the arithmetic average height deviation from a mean plane, $\mathrm{S}_{\mathrm{ds}}\left(1 / \mu \mathrm{m}^{2}\right)=$ the density of summits, and $\mathrm{S}_{\mathrm{dr}}(\%)=$ the developed surface ratio.

\section{Animals and anesthesia and surgery}

The study was approved by the Malmö/Lund regional animal ethics committee (Approval No M 314-10). Twelve adult lop-eared rabbits of mixed sexes with a mean body weight of $4.15 \mathrm{~kg}$ were used in this study. Before surgery, the skull of the rabbit was shaved and disinfected with chlorhexidine (5 mg/mL, Pharmacia AB, Stockholm, Sweden). The animals were anesthetized by an intramuscular injection of a mixture of $0.15 \mathrm{~mL} \mathrm{~kg}^{-1}$ medetomidine ( $1 \mathrm{mg} \mathrm{mL}^{-1}$ Dormitor; Orion Pharma, Sollentuna, Sweden) and $0.35 \mathrm{~mL} \mathrm{~kg}^{-1}$ ketamine hydrochloride (50 $\mathrm{mg} \mathrm{mL}^{-1}$ Ketalar; Pfizer AB, Sollentuna, Sweden). Lidocaine hydrochloride (Xylocaine $10 \mathrm{mg} / \mathrm{mL}$; AstraZeneca AB, Södertälje, Sweden) was administered as local anesthetic at each insertion site at a dose of $0.5 \mathrm{~mL}$. Sterile conditions were maintained during the surgical procedures. An incision through skin and periosteum was made along the central line on top of the skull measuring approximately $2 \mathrm{~cm}$. The periosteum was carefully removed from the bone. A trephine bur was used to make one slit in the cortical bone on each side of the midline to a depth of $0.5 \mathrm{~mm}$. The area was constantly irrigated with saline solution. Two space-maintaining devices were fitted to the bone slits and fixed with two titanium alloy screws each (De Puy Synthes 04.503.203 Ø1.5 mm $3 \mathrm{~mm}$ self-drilling) according to a randomized scheme (Figure 4). The periosteum was then sutured separately using Vicryl 4-0 continuous stitching before the skin was closed the same way. Postoperatively, buprenorphine hydrochloride $(0.5 \mathrm{~mL}$ Temgesic; Reckitt
Benckiser, Slough, UK) was administered as an analgesic for 3 days. No antibiotics were used.

\section{Preparation of samples}

At 12 weeks postoperatively, the rabbits were killed with an overdose $\left(60 \mathrm{mg} \mathrm{mL}^{-1}\right)$ of sodium pentobarbital (Apoteksbolaget AB, Stockholm, Sweden). Samples of the spacemaintaining devices, including the attaching skull bone, were retrieved and placed in 4\% formaldehyde for 24 hours, after which they were placed in $70 \%$ ethanol. All samples were processed for undecalcified ground sectioning. ${ }^{12}$ In brief, after a series of dehydrations and infiltrations in resin, the samples were embedded in light-curing resin (Technovit 7200 VLC;

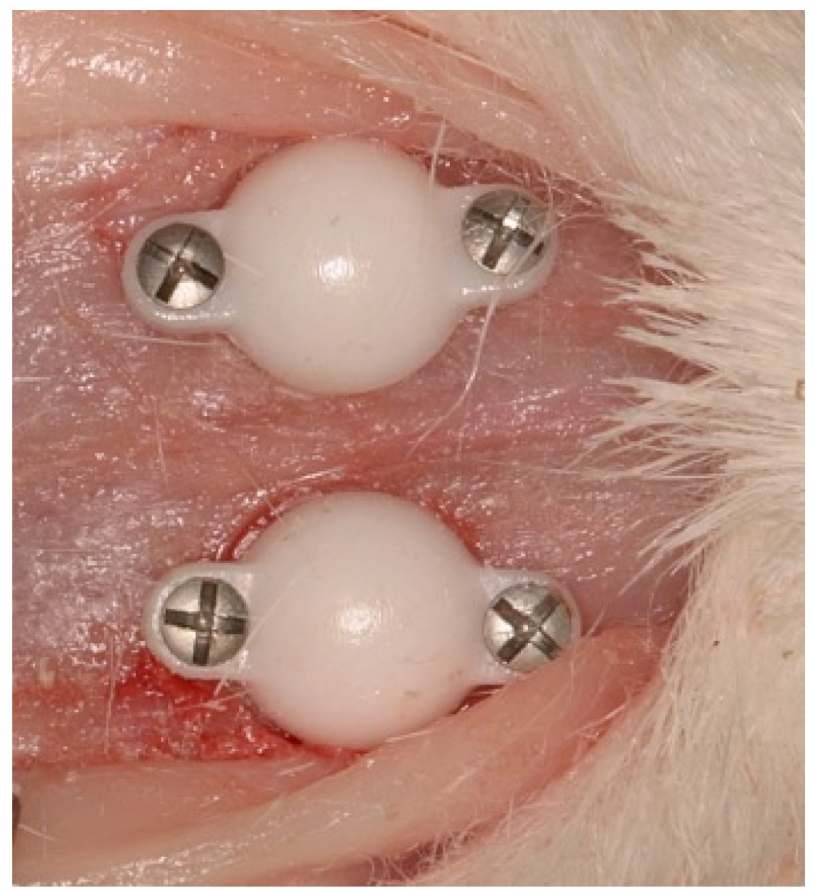

Figure 4 Ceramic space-maintaining devices attached to the skull bone of a rabbit. 
Heraeus Kulzer Wehrheim, Germany). The embedded specimens were divided into two identical blocks. Thereafter, one central cut and ground section from one of the two blocks was prepared from each sample by using Exakt sawing and grinding equipment. The sections were ground to a final thickness of approximately $25 \mu \mathrm{m}$ and stained with Toluidine Blue. It was extremely difficult to make the sample any thinner because the ceramic peeled off if ground further. The second block was prepared for SEM. The blocks were ground and polished with a fine-grained paper (SiC-Paper, grit 4000, Struers A/S, Denmark) that contained particles of $9 \mu \mathrm{m}$, $3 \mu \mathrm{m}$, and $1 \mu \mathrm{m}$. It was then coated with a thin conductive carbon layer with a thickness of approximately $1,000 \AA$ by vacuum evaporation (Agar Scientific SEM Carbon Coater, Wetzlar, Germany). These specimens were examined with SEM (JEOL JXA-8600; JEOL, Tokyo, Japan). SEM evaluated the interface between the ceramic material and newly formed bone.

\section{Histological analyses}

Histological evaluations were performed using a light microscope (Eclipse ME600; Nikon, Tokyo, Japan). The material surface on the inside of the domes was photographed using $40 \times$ magnifications. The pictures were stitched together using Adobe Photoshop Elements (Adobe Systems, San Jose, CA, USA), creating a panoramic image. The bone to material contact was measured in percentage using the free software ImageJ (National Institutes of Health, Bethesda, MD, USA). First, the total surface was measured from where the newly formed bone begun and ended. Second, the bone in contact with the material surface was measured and calculated and this figure was divided with the total surface, giving the percentage of bone in contact with the surface.

The bone volume was measured as a percentage of new bone formed related to the total volume using the same method as described with the magnification of the objective $\times 10$ and no stitching of images being needed. Only the volume of newly formed bone was measured.

Samples with more than 15 measuring points were measured twice as a control of the measuring technique. If the measures differed more than $1 \%$, the samples were measured a third time and an average of the measurements was accepted as the true result.

\section{Statistics}

All data were analyzed for statistical significance using the nonparametric Mann-Whitney test (SPSS software). The statistical significance level was set at $P<0.05$.

\section{Results}

All 24 domes had a similar design and properties and had a moderately rough inner surface with an $\mathrm{S}_{\mathrm{a}}$ of $1.11 \mu \mathrm{m}$. The microporous hydroxyapatite surface had an $\mathrm{S}_{\mathrm{dr}}$ of $85.3 \%$ and the zirconia surface had an $\mathrm{S}_{\mathrm{dr}}$ of $29.8 \%$, as shown in Table 1.

All rabbits had gained weight (mean body weight $4.53 \mathrm{~kg}$ ) during the healing period and all 24 space-maintaining devices were retrieved successfully. The results are presented in Table 2. The median percentage for bone to material contact for zirconia was $61.8 \%$ (maximum $76.7 \%$ and minimum $25.3 \%$ ). That was significantly lower than microporous hydroxyapatite, which was $88.1 \%$ (maximum $96.7 \%$ and minimum $76.3 \%)(P<0.0001)$. The median percentage of bone volume for zirconia was $16.0 \%$ (maximum $18.9 \%$ and minimum $12.2 \%$ ) and was significantly higher $(P<0.005)$ than the bone volume for microporous hydroxyapatite, which was median $11.6 \%$ (maximum $16.7 \%$ and minimum $6.6 \%$ ).

The morphological results from light microscopy are represented by Figures 5A-C, 6A and B. Two different morphologies of bone to material contact were observed using light microscopy. At the surface of the microporous hydroxyapatite, a close contact between material and new bone was seen. At the surface of zirconia, intermediate zones of about $10 \mu \mathrm{m}$ width from the material without bone contact could be seen. The bone adjacent to these zones had the same micromorphology as the inner surface of the zirconia wall. This fact presumably indicates that the bone has grown in contact with the material but been torn away from the zirconia in the grinding process. There was no presence of a soft tissue lining between the zirconia wall and the new bone. This was confirmed with the SEM analysis too.

When observing the morphology of bone growth, one could notice that the bone climbs the walls of the microporous hydroxyapatite very well, whereas the zirconia dome predominantly seems to be invaded by bone from the residual tissues.

Table I The different space-maintaining devices used

\begin{tabular}{lll}
\hline & Material & Inner surface \\
\hline Group I & Microporous & Moderately rough $\left(\mathrm{S}_{\mathrm{a}} \mathrm{I} .09 \pm 0.19 \mathrm{~mm}\right)$ \\
& hydroxyapatite & $\left(\mathrm{S}_{\mathrm{dr}} 85.3 \% \pm \mathrm{I} .6 \%\right)$ \\
Group 4 & Zirconia & Moderately rough $\left(\mathrm{S}_{\mathrm{a}} \mathrm{I} . \mathrm{I} \pm 0.09 \mathrm{~mm}\right)$ \\
& & $\left(\mathrm{S}_{\mathrm{dr}} 29.8 \% \pm \mathrm{I} .9 \%\right)$ \\
\hline
\end{tabular}

Notes: Roughness parameters of the space-maintaining devices as measured by optical interferometry. Measurements are based on an average of three devices per group that were randomly selected for analysis. Each device was measured at five positions (one at the most inner top and four at the flank areas). Results are presented as the mean \pm standard deviation. 
Table 2 Two-dimensional histological bone structures. Comparison between microporous hydroxyapatite $(\mathrm{HA})$ and zirconia

\begin{tabular}{|c|c|c|c|c|c|c|c|}
\hline & \multicolumn{3}{|c|}{ Microporous HA } & \multicolumn{4}{|c|}{ Zirconia } \\
\hline & Median & Maximum & Minimum & Median & Maximum & Minimum & $P$-value \\
\hline \multicolumn{8}{|c|}{ Bone to material contact } \\
\hline (\%) & $88.1^{*}$ & 96.7 & 76.3 & 61.8 & 76.7 & 25.3 & $<0.0001$ \\
\hline \multicolumn{8}{|c|}{ Bone volume } \\
\hline (\%) & 11.6 & 16.7 & 6.6 & $16.0 *$ & 18.9 & 12.2 & 0.005 \\
\hline
\end{tabular}

Notes: Each value represents the median, maximum, and minimum. *Significant differences sought by Mann-Whitney $U$ test; $P<0.05$.

The morphological results from SEM are represented by Figures 7A and B, 8A and B. A close contact without intervening soft tissue was seen between bone and the inner surface of the microporous hydroxyapatite using SEM. Presence of bone inside the micropores was demonstrated as well (Figure 8B). A nonunion area at the immediate interface between zirconia and bone was detected by SEM. This could not be detected at the interface between microporous hydroxyapatite. Cracks in the material were detected in the microporous hydroxyapatite but not in the zirconia.

\section{Discussion}

The purpose of this study was to evaluate the effect of two different ceramic materials as biomaterial space maintainers. As expected, new bone was regenerated in the space maintained under both types of half sphere designs, which indicates excellent biocompatibility of both zirconia and microporous hydroxyapatite.
One of the crucial aspects of GBR is the space maintenance. Most of the available membranes at hand are more or less flexible, which represents a shortcoming. The membrane should ideally possess characteristics to allow migration of bone cells without being disrupted by movement caused by oral functions, and at the same time act as a barrier for soft tissue migration, which may disturb the osteoconductive process. ${ }^{8}$

Bone tissue response to biomaterials used as barriers has earlier been described with respect to different healing patterns. If the material is biologically accepted, new bone will be created from the underlying bony surface, and a fibrous tissue of variable thickness might be formed. ${ }^{13}$

This may be considered confirmed in the present study by the results of significant differences in bone to material contact comparing zirconia and microporous hydroxyapatite. Microporous hydroxyapatite is composed of $\mathrm{Ca}_{10}\left(\mathrm{PO}_{4}\right)_{6}(\mathrm{OH})_{2}$, which is the main component of the mineral matrix of bone. ${ }^{14}$

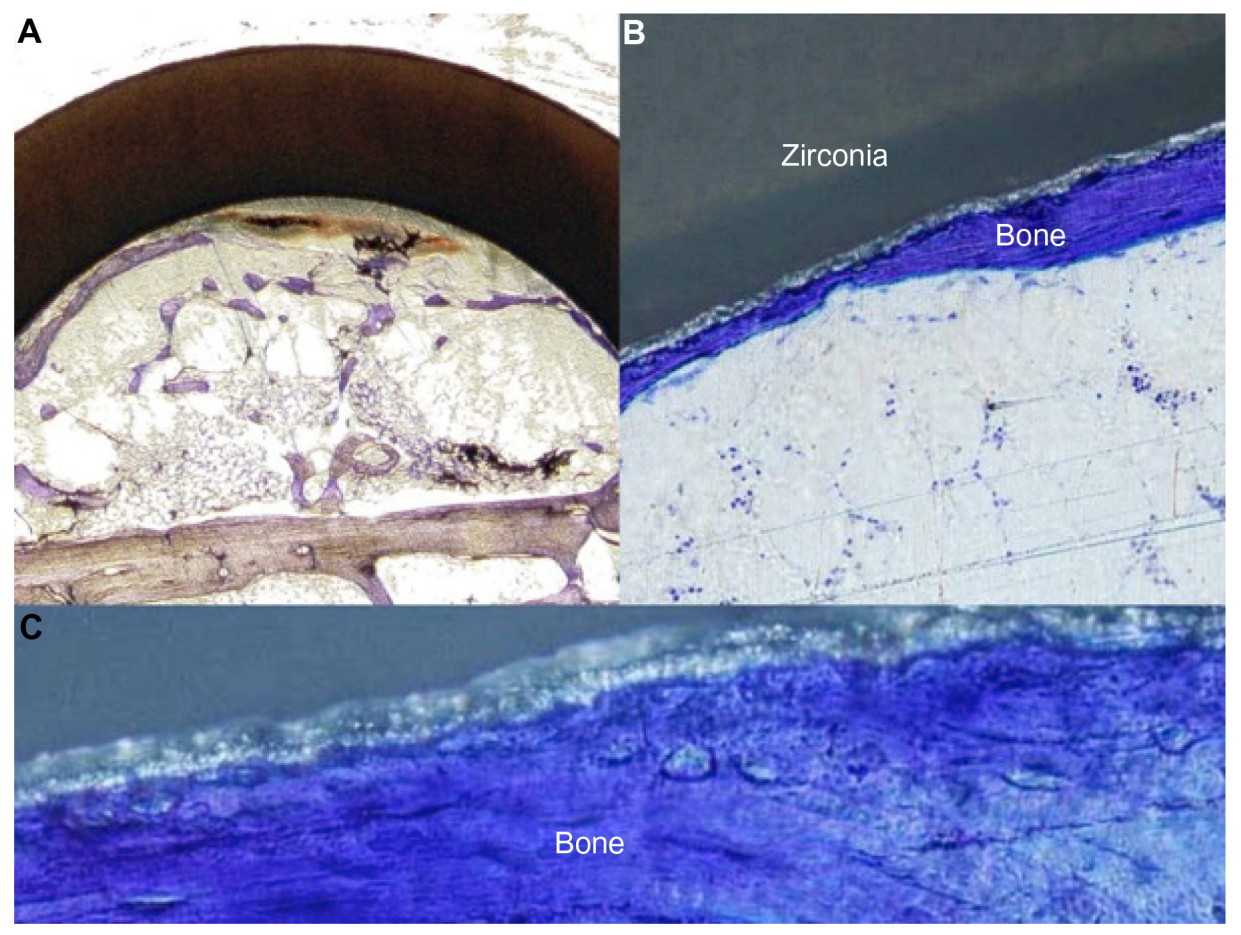

Figure 5 (A-C) Volume of newly formed bone inside the zirconia space-maintaining device and histological interface between new bone and zirconia. 


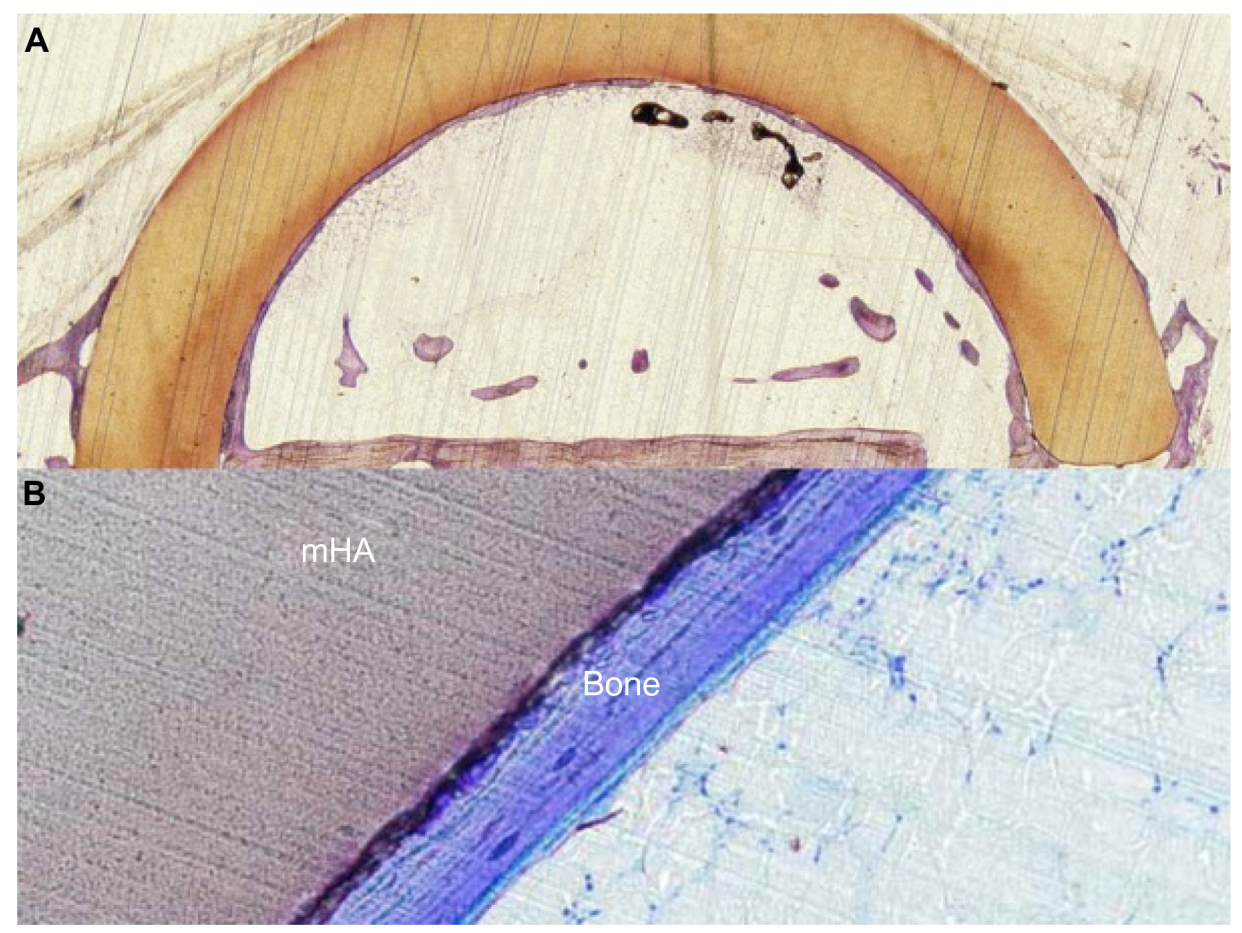

Figure 6 Volume of newly formed bone inside the hydroxyapatite space-maintaining device $(\mathbf{A})$ and histological interface between new bone and microporous hydroxyapatite (mHA) (B).

It has been discussed that the molecules contained have the ability to activate new bone formation. ${ }^{15,16}$ Zirconia, on the other hand, is an inert oxide with characteristics of hardness, high abrasion resistance, strength, and chemical inertness. ${ }^{17}$ Formation of a fibrous tissue may be expected between the material and the newly formed bone. This has been shown in other studies when using zirconia for other applications. ${ }^{18}$

The effect of the microporous structure of hydroxyapatite seems to facilitate the bone cells adhering to the material. This can be seen in the results, since there was more bone to

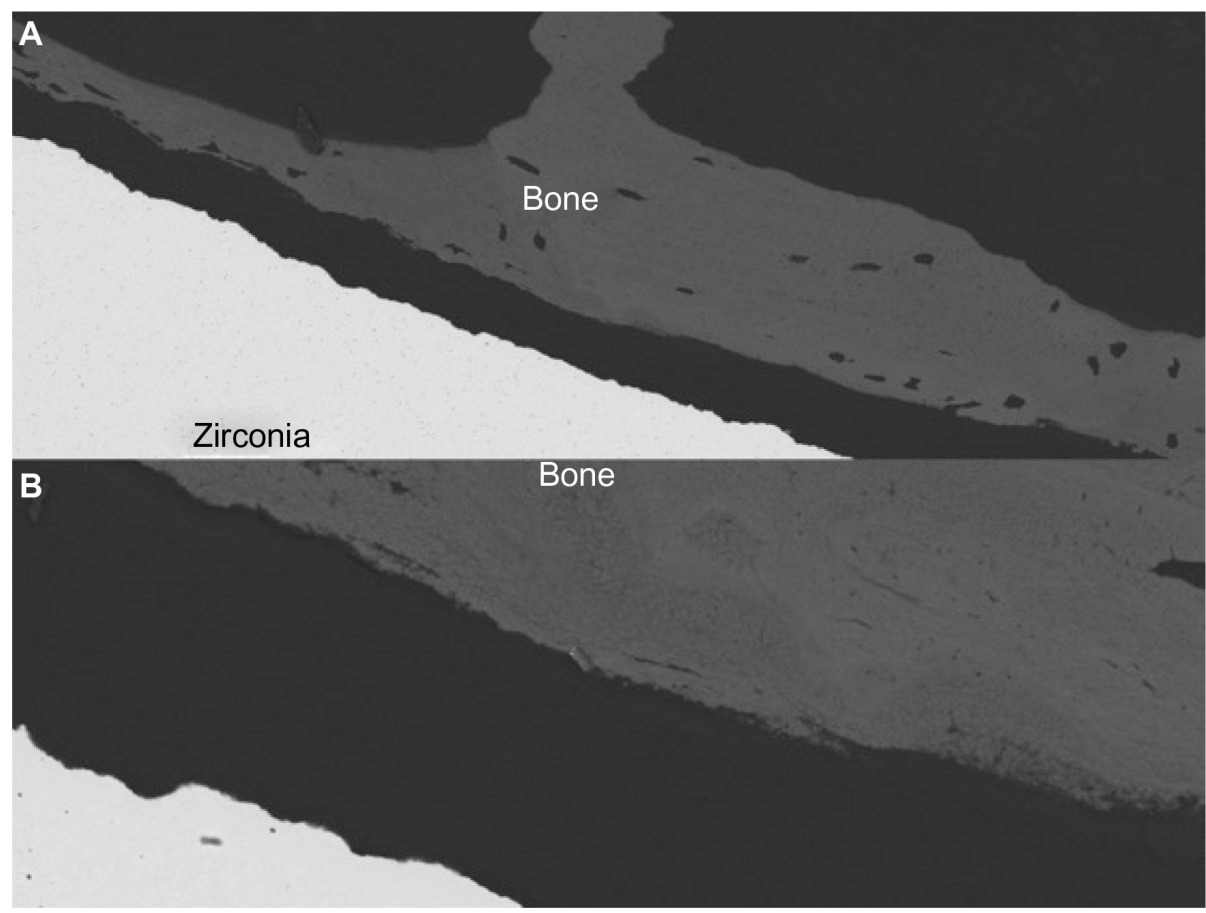

Figure 7 (A and B) Scanning electron microscopy interface between new bone and zirconia $\times 200(\mathbf{A})$ and $\times 1,000(\mathbf{B})$. 


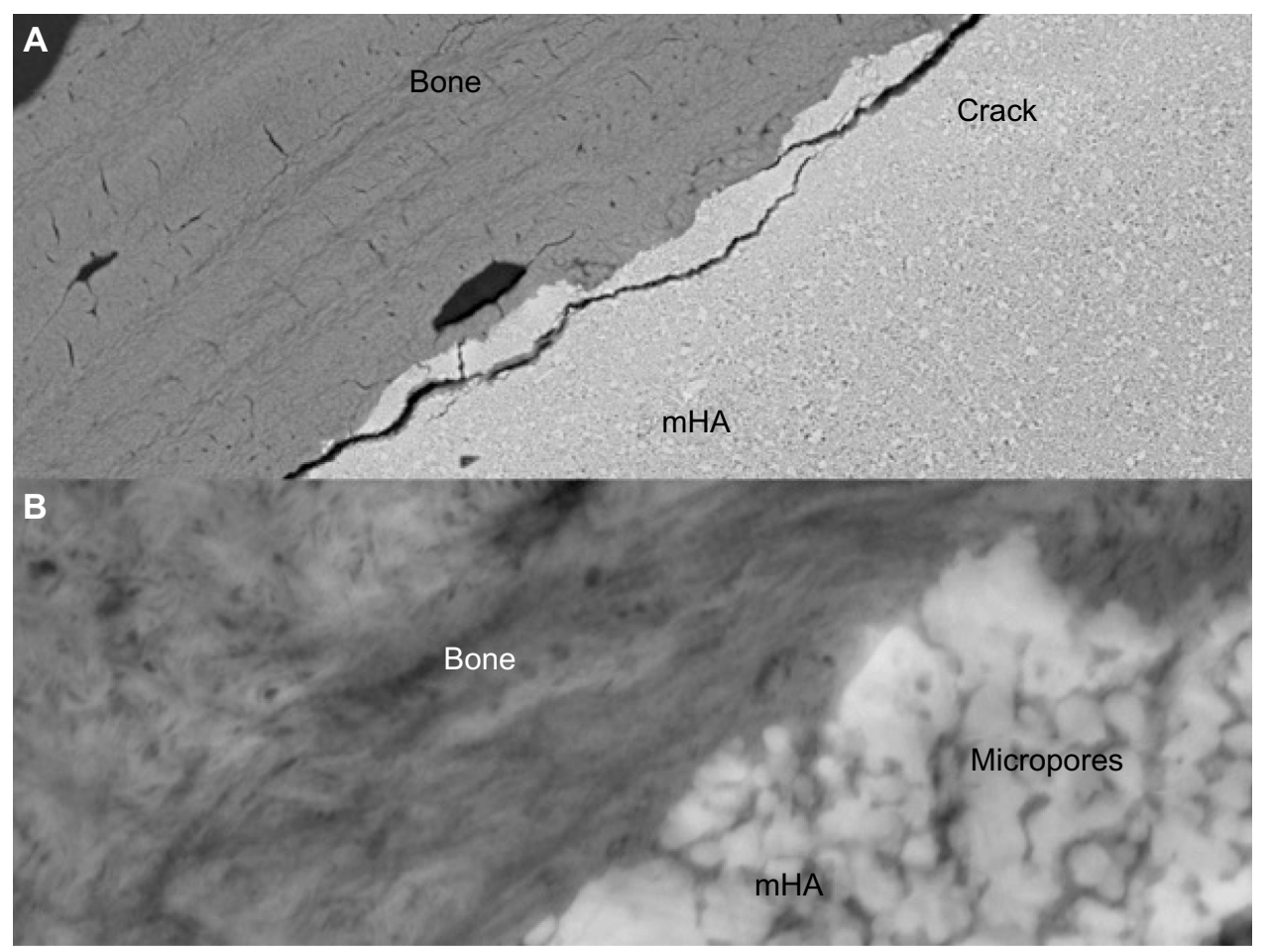

Figure 8 Scanning electron microscopy interface between new bone and microporous hydroxyapatite $(\mathrm{mHA}) \times 1,000(\mathbf{A})$ and $\times 20,000(\mathbf{B})$.

surface contact in the microporous hydroxyapatite group than in the zirconia group. The influence of surface topography on bone regeneration has been described by Wennerberg and Albrektsson, ${ }^{19}$ and surface roughness in a certain range is known to facilitate rapid and enhanced bone regeneration. ${ }^{20}$ Although previously reported mainly for titanium surfaces, it is believed that hydroxyapatite and zirconia also share characteristics of titanium, in that surface topography distinguishes itself from surface chemistry. ${ }^{21}$ As there was a difference in $\mathrm{S}_{\mathrm{dr}}$, the prominent osteoconductivity seen in the current study on hydroxyapatite and zirconia surfaces is believed to be the effect of surface topography. Malmström et $\mathrm{al}^{22}$ have earlier described this phenomenon. The study by Malmström et $\mathrm{al}^{22}$ was performed on rabbit tibia, where scaffolds made of hydroxyapatite were implanted in a bone cavity. For that reason, it is interesting that our study presents similar results. The true effect of a totally similar surface in both hydroxyapatite and zirconia would be very interesting to investigate, as it might show that the effect of the surface topography might be the dominant factor in bone regeneration rather than the surface chemistry.

The fact that the bone adheres to the microporous hydroxyapatite could mean that the space maintainer would be difficult to remove in a clinical application and vice versa regarding zirconia. This could implicate that zirconia would be a more suitable material if the purpose would be to remove the space maintainer before using the newly formed bone Hydroxyapatite is sometimes available in a mix with tricalcium phosphate. Tricalcium phosphate gradually dissolves in the body and is replaced by the surrounding tissues, ${ }^{16}$ and the hydroxyapatite is left in the bone tissues as a natural scaffold. In that case, it might be an advantage to leave the microporous hydroxyapatite in situ and accept it as a part of the newly formed bone. Our experiment had too short a follow-up time to show such an event, but since this would be of potential clinical interest, the possible resorption of tricalcium phosphate-containing hydroxyapatite seems suitable for future experiments.

All domes were considered totally occlusive. The periosteum had no possibility to interact with the forming bone inside the created space. Although it has been suggested by Lundgren et $\mathrm{al}^{23}$ that there exists a difference in the kinetics of bone regeneration when domes with perforations of different size are used, Schmid et $\mathrm{al}^{24}$ claimed the opposite when evaluating the involvement of periosteum for bone formation. The authors compared a titanium dome that was totally occlusive with a titanium dome that was open but was covered with a commercially available membrane with a particular pore size. It was indicated that the communication with the periosteum did not influence the bone formation within the dome and that a space maintainer did not need to have any permeability, which was confirmed in the present study. 
As the results indicate, bone cells climb the inner surface of microporous hydroxyapatite better than on zirconia. Similar experiments using titanium domes have shown that the bone volume fills up the total volume of the domes if just given time, although that study was examining the influence of barrier occlusiveness. ${ }^{23}$ This defines the bone conductivity of a stable fixed membrane regardless of biologically accepted material and it defines as well the bone conductivity of microporous hydroxyapatite.

We have focused on showing the potential advantages of ceramic domes regarding design, and have standardized all variables such as size, permeability, and surface characteristics, which is the reason that neither ePTFE nor titanium mesh was used as control materials.

In conclusion, the results of the current study demonstrated that the ceramic space-maintaining devices permit new bone formation and osteoconduction within the dome regardless of ceramic material used. Furthermore, it shows different patterns of bone growth when regarding chosen material with different surface characteristics. Further studies are needed to determine the optimal surface topography and the optimal macroscopic design in combination of material chemistry (ie, hydroxyapatite or zirconia) of the membranes (domes). Moreover, the absolute limit of the vertical bone regeneration with this technique needs to be clarified, and there is an importance for clinical studies to compare this method with standard procedures.

\section{Disclosure}

The authors report no conflicts of interest in this work.

\section{References}

1. Albrektsson T, Branemark PI, Hansson HA, Lindstrom J. Osseointegrated titanium implants. Requirements for ensuring a long-lasting, direct bone-to-implant anchorage in man. Acta Orthop Scand. 1981;52(2): $155-170$.

2. Branemark PI, Adell R, Albrektsson T, Lekholm U, Lundkvist S, Rockler B. Osseointegrated titanium fixtures in the treatment of edentulousness. Biomaterials. 1983;4(1):25-28.

3. Adell R, Lekholm U, Grondahl K, Branemark PI, Lindstrom J, Jacobsson M. Reconstruction of severely resorbed edentulous maxillae using osseointegrated fixtures in immediate autogenous bone grafts. Int J Oral Maxillofac Implants. 1990;5(3):233-246.

4. Gottlow J, Nyman S, Karring T, Lindhe J. New attachment formation as the result of controlled tissue regeneration. J Clin Periodontol. 1984; 11(8):494-503.

5. Nyman S, Lindhe J, Karring T, Rylander H. New attachment following surgical treatment of human periodontal disease. J Clin Periodontol. 1982;9(4):290-296.
6. Lang NP, Hammerle CH, Bragger U, Lehmann B, Nyman SR. Guided tissue regeneration in jawbone defects prior to implant placement. Clin Oral Implants Res. 1994;5(2):92-97.

7. von Arx T, Hardt N, Wallkamm B. [The TIME technic. Local osteoplasty with micro-titanium mesh (TIME) for alveolar ridge augmentation]. Schweiz Monatsschr Zahnmed. 1995;105(5):650-663. French and German.

8. Hammerle $\mathrm{CH}$, Jung RE. Bone augmentation by means of barrier membranes. Periodontol 2000. 2003;33:36-53.

9. von Arx T, Kurt B. Implant placement and simultaneous peri-implant bone grafting using a micro titanium mesh for graft stabilization. Int $J$ Periodontics Restorative Dent. 1998;18(2):117-127.

10. Abrahamsson P, Walivaara DA, Isaksson S, Andersson G. Periosteal expansion before local bone reconstruction using a new technique for measuring soft tissue profile stability: a clinical study. J Oral Maxillofac Surg. 2012;70(10):e521-e530.

11. Carter CB, Norton MG. Ceramic Materials: Science and Engineering. 2nd ed. New York: Springer; 2013.

12. Donath K. Die trenn-dünnschliff-Technik zur Herstellung histologischer Präparate von nicht schneidbaren Geweben und Materialien. Der Präparator. 1988;(34):197-206.

13. Schenk RK, Buser D, Hardwick WR, Dahlin C. Healing pattern of bone regeneration in membrane-protected defects: a histologic study in the canine mandible. Int J Oral Maxillofac Implants. 1994;9(1):13-29.

14. Robinson RA. Bone tissue: composition and function. Johns Hopkins Med J. 1979;145(1):10-24.

15. Brighton CT, Hunt RM. Histochemical localization of calcium in the fracture callus with potassium pyroantimonate. Possible role of chondrocyte mitochondrial calcium in callus calcification. J Bone Joint Surg Am. 1986;68(5):703-715.

16. Fu K, Xu Q, Czernuszka J, Triffitt JT, Xia Z. Characterization of a biodegradable coralline hydroxyapatite/calcium carbonate composite and its clinical implementation. Biomed Mater. 2013;8(6):065007.

17. Ratner BD. Biomaterials Science: An Introduction to Materials in Medicine. 2nd ed. Boston, MA: Elsevier Academic Press; 2004.

18. Malmström J. On bone regeneration in porous bioceramics: studies in humans and rabbits using free form fabricated scaffolds [Diss (sammanfattning) Göteborg Göteborgs Universitet, 2007]. Göteborg: Institute of Clinical Sciences, Department of Biomaterials, Göteborg University; 2007.

19. Wennerberg A, Albrektsson T. On implant surfaces: a review of current knowledge and opinions. Int J Oral Maxillofac Implants. 2010;25(1): $63-74$.

20. Wennerberg A, Albrektsson T. Effects of titanium surface topography on bone integration: a systematic review. Clin Oral Implants Res. 2009; 20 Suppl 4:172-184.

21. Jimbo R, Sotres J, Johansson C, Breding K, Currie F, Wennerberg A. The biological response to three different nanostructures applied on smooth implant surfaces. Clin Oral Implants Res. 2012;23(6):706-712.

22. Malmström J, Adolfsson E, Arvidsson A, Thomsen P. Bone response inside free-form fabricated macroporous hydroxyapatite scaffolds with and without an open microporosity. Clin Implant Dent Relat Res. 2007;9(2):79-88.

23. Lundgren A, Lundgren D, Taylor A. Influence of barrier occlusiveness on guided bone augmentation. An experimental study in the rat. Clin Oral Implants Res. 1998;9(4):251-260.

24. Schmid J, Hämmerle CH, Olah AJ, Lang NP. Membrane permeability is unnecessary for guided generation of new bone. An experimental study in the rabbit. Clin Oral Implants Res. 1994;5(3):125-130. 


\section{Publish your work in this journal}

Clinical, Cosmetic and Investigational Dentistry is an international, peer-reviewed, open access, online journal focusing on the latest clinical and experimental research in dentistry with specific emphasis on cosmetic interventions. Innovative developments in dental materials, techniques and devices that improve outcomes and patient satisfaction and preference will be highlighted. The manuscript management system is completely online and includes a very quick and fair peerreview system, which is all easy to use. Visit http://www.dovepress. com/testimonials.php to read real quotes from published authors.

Submit your manuscript here: http://www.dovepress.com/clinical-cosmetic-and-investigational-dentistry-journal 